\title{
A!
}

This is an electronic reprint of the original article.

This reprint may differ from the original in pagination and typographic detail.

Littunen, Kuisma; Mai-Gisondi, Galina; Seppälä, Jukka; Master, Emma R.

\section{Enzymatically Debranched Xylans in Graft Copolymerization}

Published in:

Biomacromolecules

DOI:

10.1021/acs.biomac. 7 b00229

Published: 08/05/2017

Document Version

Peer reviewed version

Published under the following license:

Unspecified

Please cite the original version:

Littunen, K., Mai-Gisondi, G., Seppälä, J., \& Master, E. R. (2017). Enzymatically Debranched Xylans in Graft

Copolymerization. Biomacromolecules, 18(5), 1634-1641. https://doi.org/10.1021/acs.biomac.7b00229

This material is protected by copyright and other intellectual property rights, and duplication or sale of all or part of any of the repository collections is not permitted, except that material may be duplicated by you for your research use or educational purposes in electronic or print form. You must obtain permission for any other use. Electronic or print copies may not be offered, whether for sale or otherwise to anyone who is not an authorised user. 


\section{Enzymatically debranched xylans in graft}

\section{2 copolymerization.}

3 Kuisma Littunen ${ }^{1+}$, Galina Mai-Gisond ${ }^{2+}$, Jukka Seppäläl, Emma R. Master ${ }^{2,3 *}$

$4 \quad{ }^{1}$ Department of Chemical and Metallurgical Engineering, Aalto University, 00076 Aalto, Finland

$5 \quad{ }^{2}$ Department of Bioproducts and Biosystems, Aalto University, 00076 Aalto, Finland

$6{ }^{3}$ Department of Chemical Engineering and Applied Chemistry, University of Toronto, 200 College

7 Street, Toronto, Ontario, M5S 3E5, Canada.

8

9 KEYWORDS. Wheat arabinoxylan, $\alpha$-arabinofuranosidases, graft copolymerization, glycidyl

10 methacrylate, QCM-D

12 K.L. and G.M. contributed equally to this work.

13 *Corresponding author:

14 Emma R. Master

15 Telephone: 416-946-7891

16 Fax: 416-978-8605

17 Email: emma.master@aalto.fi; emma.master@utoronto.ca 


\section{ABSTRACT}

2 Wheat arabinoxylan was treated with two $\alpha$-arabinofuranosidases exhibiting different mode of 3 action to create three different polymeric substrates. These three substrate preparations were

4 characterized by xylopyranose backbone sugars that are: (1) singly substituted by arabinose at C2

5 or C3, (2) doubly substituted by arabinose at C2 and C3, and (3) largely unsubstituted. All xylan

6 preparations were grafted with glycidyl methacrylate using cerium ammonium nitrate and then

7 evaluated in terms of graft yield and adsorption to cellulose surfaces. The highest graft yield was

8 observed for the xylan preparation characterized by a largely unsubstituted xylopyranose

9 backbone. Furthermore, QCM-D analyses revealed that grafted xylans exhibited a two-stage

10 desorption pattern, which was not seen with the ungrafted xylans and was consistent with increased

11 water sorption. Accordingly, this study demonstrates the potential of arabinofuranosidases to

12 increase the yield and influence the viscoelastic properties of grafted xylans used as bio-based

13 cellulose coatings. 


\section{INTRODUCTION}

2 Hemicelluloses comprise $20-30 \%$ of the total mass of annual and perennial plants. ${ }^{1}$ The main

3 hemicellulose fraction in hardwood trees is acetylated glucuronoxylan, which consists of a $\beta$ -

4 (1 $\rightarrow 4)$-linked D-xylopyranosyl $(\mathrm{Xyl} p)$ backbone that is partially substituted at O-2 positions with

$5 \alpha$-D-glucuronic acid (GlcAp) or 4-O-methyl GlcAp (MeGlcAp), and at O-2 positions and/or O-3

6 positions with acetyl substituents. ${ }^{2-4}$ Xylan from conifers (softwoods) and vegetative tissue of

7 monocots (e.g., cereals and grasses) similarly comprise a $\beta$-(1 $\rightarrow 4)$-linked Xyl $p$ backbone with

8 varying MeGlcAp and $\alpha$-L-arabinofuranosyl (Araf) contents, ${ }^{2}$ whereas endosperm cell walls of

9 cereals largely comprise arabinoxylan that lack MeGlcAp substituents. ${ }^{5}$

10 The physicochemical characteristics and functional properties of xylans depend on their

11 molecular mass, branching and macroscopic structure. Arabinoxylans are known to exhibit high

12 intrinsic viscosity that is affected by the fraction of di-substituted over mono-substituted Xylp

13 substituents. ${ }^{6}$ It is also reported that arabinoxylan solubility is dependent on both molecular weight

14 and type and arrangement of xylan side groups. ${ }^{6}$

15 Due to the functional properties and wide availability of xylans, a broad range of applications

16 have already been considered, including use as food additives, hydrogels and aerogels for nutrient

17 and drug delivery, wet-strength additives to cellulose pulp, and films for wound dressing and

18 packaging materials. ${ }^{6-12}$ Barrier properties, namely oxygen, grease, and water vapor permeability,

19 along with mechanical properties are especially important to these applications. ${ }^{7,8,12-20}$ Selective

20 extraction of xylan-rich fractions from wood hydrolysates can yield xylan films and coatings with

21 competitive oxygen barrier properties. ${ }^{9,21}$ Additional performance attributes, such as water vapour

22 transmission, can also be enhanced through use of bio-based additives including lipids, ${ }^{13}$

23 sorbitol, ${ }^{18,22}$ glycerol, ${ }^{14}$ carboxymethyl cellulose and chitosan; ${ }^{23}$ common mineral additives such 
1 as layered silicates were also shown to significantly improve oxygen and water barrier properties

2 of xylan films. ${ }^{24}$ Alternatively, the hydrophilic nature xylans can be controlled through direct

3 chemical modification of the xylan backbone, for example through esterification, etherification, as

4 well as oxidative or reductive coupling, to introduce hydrophobic groups into the xylan

5 backbone. ${ }^{7,12,25,26}$ Farhat et al provide a recent review of process options and modification

6 pathways to generating water-resistant hemicellulosic materials. ${ }^{12}$

7 Accessory hemicellulases can also be used to modify xylan branching structure, and thereby

8 alter xylan solubility, rheology, and adherence to other biopolymers. In particular, $\alpha$-L-

9 arabinofuranosidases, $\alpha$-glucuronidases, acetyl xylan esterases, feruloyl esterases, as well as

10 glucuronoyl esterases, target the branching substituents present in different xylan types. ${ }^{27}$

11 Considering $\alpha$-L-arabinofuranosidases in more detail, glycoside hydrolase (GH) family GH62

12 comprise enzymes that act only on mono-substituted $\mathrm{Xyl} p,{ }^{28}$ and are termed AXH-m arabinoxylan

13 arabinofuranohydrolases. Alternatively, family GH43 includes arabinofuranosidases with ability

14 to remove Araf substituents from the O-3 of position of doubly substituted Xylp (i.e., AXHd3

15 activity). ${ }^{29}$ Reducing Araf content in arabinoxylans was previously shown to increase the

16 crystallinity of resulting films, which can improve water barrier properties. ${ }^{9,16,17,30,31}$ Moreover, by

17 using a combinantion of arabinofuranosidases with distinct regioselectivity, both Araf to Xylp ratio

18 as well as Araf position were shown to impact the water-solubility of resulting arabinoxylans and

19 the crystallinity of corresponding films. ${ }^{16,31-33}$ In particular, Heikkinen et al. ${ }^{33}$ showed that the

20 removal of $\alpha$-L-Araf residues $(1 \rightarrow 3)$-linked to monosubstituted $\beta$-D-Xyl $p$ sugars had the greatest

21 affect on the barrier properties of arabinoxylan based films, while Köhnke et al. ${ }^{32}$ showed that a

22 similar treatment increased xylan adsorption to cellulose. 
1 Previous studies have investigated xylan adsorption to cellulose through empirical and

2 computational analyses. For example, adsorption isotherms and QCM-D analyses were previously

3 performed to compare the association of various xylan sources (as well as other hemicelluloses)

4 to microcrystalline cellulose (Avicel), bacterial cellulose, and nano-fibrillated cellulose. ${ }^{34-36}$

5 Furthermore, molecular dynamics simulations of xylan adsorption to cellulose have been

6 performed, which considered xylans from the secondary cell walls of the gymnosperm lineages

7 that are substituted with both Araf and MeGlcAp, and of xylans from Gnetophyta that contain

8 acetyl groups instead of Araf substitutions. ${ }^{37}$ Both the empirical and computational analyses

9 confirmed that high molecular weight and unsubstituted xylans show highest affinity to cellulose;

$10^{34-36}$ molecular dynamics simulations also predict impacts of substituent distribution on the

11 stability of cellulose associations. . $^{37,38}$

12 In the present study, two different arabinofuranosidases were used to selectively remove distinct

$13 \alpha$-L-Araf substituents from wheat arabinoxylan (WAX) prior to graft copolymerization with

14 glycidyl methacrylate (GMA). GMA was selected as the monomer for the grafting experiments as

15 it was previously shown to react well with polysaccharides, including hemicelluloses, ${ }^{18}$ and

16 because the epoxy groups introduced through GMA grafting creates sites that can be further

17 chemically modified depending on the end use. ${ }^{39}$ Whereas the GH62 $\alpha$-L-arabinofuranosidase

18 from Streptomyces thermoviolaceus (SthAbf62A) was selected to remove $\alpha$-L-Araf residues

19 linked to mono-substituted $\beta$-D-Xylp sugars, ${ }^{40}$ the GH43 $\alpha$-L-arabinofuranosidase from

20 Bifidobacterium sp. (AXHd3) was selected to remove $\alpha$-L-Araf residues $(1 \rightarrow 3)$-linked to di-

21 substituted $\beta$-D-Xylp ${ }^{29}$ The effect of enzyme pretreatment on xylan co-polymer solubility, yield

22 and adsorption to cellulose was then evaluated. 


\section{Materials}

3 Wheat arabinoxylan (P-WAXYL; Lot 120601a and 70502a) was purchased from Megazyme

4 (Araf:Xylp ratio 38:62). The $\alpha$-L-arabinofuranosidase from Bifidobacterium sp. (glycoside

5 hydrolase $(\mathrm{GH})$ family 43; E-AFAM2; AXHd3); endo-1,4- $\beta$-D-xylanase from Neocallimastix

6 patriciarum (GH11; E- XYLNP), and $\beta$-xylosidase from Selenomonas ruminantium (GH43; E-

7 BXSR-3KU) were also purchased from Megazyme. The GH62 $\alpha$-L-arabinofuranosidases from

8 Streptomyces thermoviolaceus (SthAbf62A and SthAbf62A_E213A) were provided by the

9 University of Toronto. ${ }^{40}$ Glycidyl methacrylate (GMA) and cerium ammonium nitrate (CAN) as

10 well as 14,000 Da dialysis membrane (D9402) were purchased from Sigma-Aldrich. Ethanol was

11 procured from Altia and acetone from VWR.

\section{Enzymatic preparation of wheat arabinoxylan prior to grafting}

13 Wheat arabinoxylan (WAX) was separately treated with AXHd3, SthAbf62A, and AXHd3 +

14 SthAbf62A, to generate three xylan samples, namely WAX_AXHd3, WAX_SthAbf62A, and

15 WAX_AXHd3_SthAbf62A, respectively (Figure 1). WAX_AXHd3, is characterized by $\beta$-D-

16 Xyl $p$ backbone sugars that are singly substituted by $\alpha$-L-Ara $f(1 \rightarrow 3)$ and $\alpha$-L-Ara $f(1 \rightarrow 2)$ residues.

17 In WAX_SthAbf62A, $\beta$-D-Xyl $p$ backbone sugars are doubly substituted by $\alpha$-L-Ara $f(1 \rightarrow 3)$ and $18 \alpha$-L-Araf $(1 \rightarrow 2)$ residues. Finally, WAX_AXHd3_SthAbf62A is characterized by a largely 19 unsubstituted $\beta$-D-Xyl $p$ backbone, and was produced by first creating WAX-AXHd3 followed by 20 treatment with SthAbf62A. 

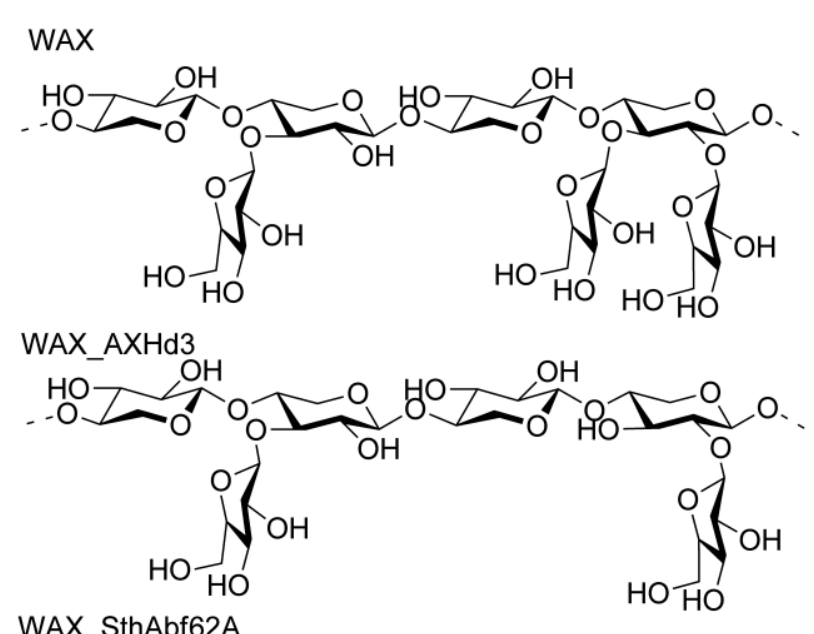

WAX_SthAbf62A
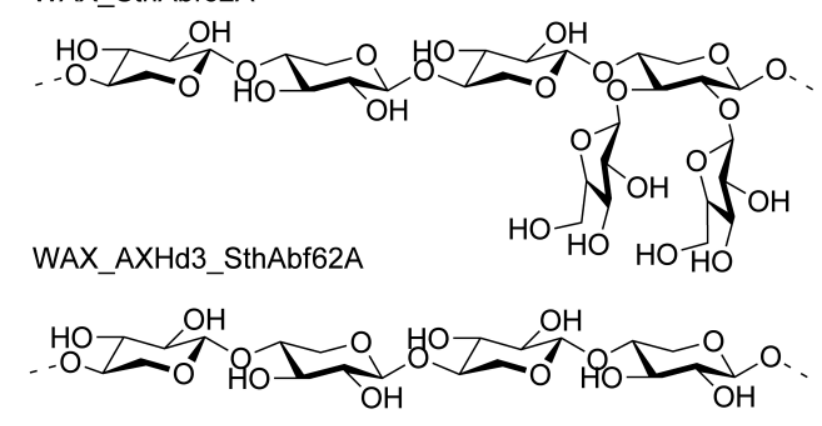

2 Figure 1. Schematic representation of WAX prior to enzyme treatment, after treatment with

3 AXHd3, after treatment with SthAbf62A, and after treatment with AXHd3 and SthAbf62A.

\section{Enzymatic xylan modifications}

5 To prepare each of the above described xylan samples, a $1 \%$ WAX solution was suspended in

$630 \mathrm{~mL} 50 \mathrm{mM}$ sodium phosphate buffer (pH 6.5); to generate WAX_AXHd3, $375 \mu \mathrm{g}(25 \mathrm{U})$ of

7 AXHd3 were added to the solution, which was then incubated in a shaking water bath ( $80 \mathrm{rpm})$ at

$840{ }^{\circ} \mathrm{C}$ for $24 \mathrm{~h}$ before adding additional $150 \mu \mathrm{g}(10 \mathrm{U})$ of $\mathrm{AXHd} 3$ and continuing the incubation

9 for another $24 \mathrm{~h}$. WAX_SthAbf62A was prepared as described above, except that AXHd3 was

10 replaced by $300 \mu \mathrm{g}$ of SthAbf62A. Finally, AXHd3_SthAbf62A was prepared by treating

11 WAX_AXHd3 with $300 \mu \mathrm{g}$ of SthAbf62A. After $24 \mathrm{~h}$, an additional $300 \mu \mathrm{g}$ of SthAbf62A was 
1 added and the reaction was incubated for another $24 \mathrm{~h}$. Control treatments used buffer alone or the

2 SthAbf62A E213A catalytic mutant.

3 Following enzyme treatment, xylan preparations were boiled for $10 \mathrm{~min}$ to denature the applied

4 enzymes, and precipitated using $60 \%$ ethanol. The xylan precipitate was recovered by

5 centrifugation for $30 \mathrm{~min}$ at 15,000 rpm (SS-34 rotor, Sorvall centrifuge) and then suspended in

6 up $50 \mathrm{~mL}$ milli-Q water. The ethanol precipitation procedure ${ }^{41}$ was then repeated prior to freezing

7 in liquid nitrogen and lyophilization. In cases where the ash content was $>15 \%$, dialysis was

8 performed using a 14,000 Da dialysis membrane against milli-Q water prior to lyophilization.

$9 \quad$ Quantification of released arabinose

10 The extent of Araf released to produce WAX_AXHd3, WAX_SthAbf62A, and

11 WAX_AXHd3_SthAbf62A was quantified using the L-Arabinose/D-Galactose Assay Kit (K-

12 ARGA; Megazyme). Araf release was further quantified by high performance liquid

13 chromatography (HPLC) using Aminex HPX-87P (Bio-RAD) column equipped with a de-ashing

14 Refill Cartridge (Bio-Rad) pre-column kept at $85^{\circ} \mathrm{C}$; analytes were eluted with milli-Q water at a

15 flow rate of $0.4 \mathrm{~mL} / \mathrm{min}$. L-Arabinose was used as the standard $(0.1-0.8 \mathrm{~g} / \mathrm{L})$ and eluted with a

16 retention time of $24.8 \mathrm{~min}$.

$17 \quad{ }^{1} \mathbf{H}$ NMR analyses

18 WAX samples before and after enzyme treatment were analyzed by ${ }^{1} \mathrm{H}$ NMR to confirm 19 selective removal of $\alpha$-L-Araf $(1 \rightarrow 3)$ from di-substituted Xyl $p$ backbone residues and $\alpha$-L-Ara $f$

$20(1 \rightarrow 2)$ from mono-substituted Xylp backbone residues by SthAbf62A and AXHd3, respectively.

21 To sharpen corresponding diagnostic peaks, an endo-1,4- $\beta$-D-xylanase from $N$. patriciarum (E-

22 XYLNP; GH11, Megazyme) was used to hydrolyze each xylan sample prior to analysis. 
1 Specifically, $0.6 \mathrm{~mL}$ of $1 \%$ xylan solutions were precipitated by adding $1.3 \mathrm{~mL}$ of $99.5 \%$ ethanol

2 and centrifugation at $15,000 \mathrm{rpm}$ for $10 \mathrm{~min}$. The pellet was suspended in $0.6 \mathrm{~mL}$ of water and

3 again precipitated with $1.2 \mathrm{~mL}$ of $99.5 \%$ ethanol. The pellet was suspended in $0.6 \mathrm{~mL}$ of $10 \mathrm{mM}$

4 (3-(N-morpholino) propanesulfonic acid) (MOPS) buffer $(\mathrm{pH} 7.0)$ and then treated with $2.5 \mathrm{U}$ of

5 E-XYLNP at $50{ }^{\circ} \mathrm{C}$. After $24 \mathrm{~h}$, an additional $2.5 \mathrm{U}$ E-XYLNP was added and the reaction was

6 incubated for another $24 \mathrm{~h}$. Reaction mixtures were subsequently boiled for $15 \mathrm{~min}$ to inactivate

7 the endoxylanase, then lyophilized and dissolved in $0.6 \mathrm{~mL}$ of $\mathrm{D} 2 \mathrm{O}$ twice.

8 NMR spectra were subsequently obtained in D2O at $25^{\circ} \mathrm{C}$ using a Bruker Avance III $400 \mathrm{MHz}$

9 spectrometer, with a scan number of 16 , pulse angle of $30^{\circ}$, and relaxation delay of $12 \mathrm{~s}$. The data

10 were processed using TopSpin 3.0 software. Previously assigned peaks in ${ }^{1} \mathrm{H}$ NMR spectra of

11 arabinoxylans were used for data interpretation. ${ }^{16,32,40,42-45}$ The methylene protons at position 2 of

12 MOPS (2.035 ppm) were used as the internal standard. The degree of Araf substitution was

13 determined from ${ }^{1} \mathrm{H}$ NMR spectra by using the ratio between the standard peak and the anomeric

14 proton peaks at approximately $(5.27-5.35 \mathrm{ppm})$ for L-Araf $(1 \rightarrow 3)$ in mono-substituted Xylp,

15 (5.17-5.23) for $\alpha$-L-Ara $f(1 \rightarrow 2)$ in mono- and di-substituted Xyl $p$, and (5.13-5.17 ppm) for $\alpha$-L-

$16 \operatorname{Ara} f(1 \rightarrow 3)$ in di-substituted Xylp. The ratio was then compared to an unmodified WAX sample

17 with known arabinose content to obtain the degree of substitution (DS) of each sample.

18 Particle size and turbidity

19 The particle size distribution of each xylan preparation was analyzed by dynamic light scattering

20 (DLS) using a Zetasizer Nano instrument (Malvern Instruments, UK). The light scattering was

21 measured at xylan concentrations between 0.1 and $1.0 \mathrm{~g} / \mathrm{L}$ to ensure sufficient scattering $(>100$

22 kcps) while preventing multiple scattering (one photon being scattered by several particles). 
1 Turbidity of the solutions was determined at $0.5 \mathrm{~g}$ xylan/L by measuring light transmittance at 700

2 nm wavelength, using a Helios $\beta$ UV/VIS spectrometer (Unicam, UK).

3 Thermogravimetric analysis (TGA)

4 The moisture and ash content of each xylan preparation was measured by using a TGA Q500

5 instrument (TA Instruments, New Castle, DE). Approximately $5 \mathrm{mg}$ sample was kept isothermal

6 for $20 \mathrm{~min}$ first at $105^{\circ} \mathrm{C}$ in a nitrogen atmosphere and then at $650{ }^{\circ} \mathrm{C}$ in an oxygen atmosphere.

7 Dry weight and ash content were determined at the end of the isothermal periods.

\section{Graft copolymerization}

9 Xylans were grafted by a method described by Littunen et al. ${ }^{26}$ Briefly, xylan $(0.20 \mathrm{~g})$ was 10 dissolved in deionized milli-Q water $(95 \mathrm{~mL})$ in a round-bottom flask. Nitrogen was bubbled 11 through the solution to remove dissolved oxygen prior to the synthesis. Dissolved CAN ( $0.10 \mathrm{~g}$, $120.18 \mathrm{mmol}$ ) was injected, and the flask was heated with an oil bath to $35^{\circ} \mathrm{C}$. After $15 \mathrm{~min}$, GMA $13(0.57 \mathrm{~g}, 4.0 \mathrm{mmol})$ was injected, and the reaction was carried out for $60 \mathrm{~min}$; the subsequent 14 separation procedure is summarized in Scheme 1. Briefly, following grafting, the reaction medium 15 was centrifuged for $30 \mathrm{~min}$ at $4,000 \mathrm{rpm}$ and the separated solids were washed four times with 16 acetone, leaving the non-soluble copolymer (NS). The supernatant was precipitated with acetone 17 using 1:4 water-acetone ratio to obtain the water-soluble copolymer (WS). The remaining acetone 18 fraction could contain partially acetone/water-soluble soluble copolymer (AS) as well as the GMA 19 homopolymer (HP). To separate these two products, the acetone fraction was evaporated to remove 20 the residual water, re-dissolved in approximately $10 \mathrm{~mL}$ of acetone, and then centrifuged for 10 $21 \mathrm{~min}$ at 4,000 rpm. The pellet comprised the copolymer that was soluble in $80 \%$ acetone, whereas 22 the supernatant would contain the homopolymer (HP) soluble in $100 \%$ acetone. To quantify the 
1 HP formed in each reaction, the corresponding fraction was precipitated with $90 \%$ methanol and

2 dried in vacuum at $30{ }^{\circ} \mathrm{C}$ overnight and weighed. Each experiment was repeated at least once.

3 Since the xylans were known to contain variable amounts of moisture and inorganic compounds,

4 these were determined by TGA and subtracted from the total mass. The relative amount of grafted

5 polymer (graft yield, G\%) was calculated using formula 1.

$6 \quad G \%=\frac{m_{N S}+m_{W S}-m_{X}}{m_{X}} \times 100 \%$

7 where $m_{N S}$ is the mass of the insoluble product, $m_{W S}$ is the mass of the water-soluble product, and

$8 m_{X}$ is the corrected mass of xylan.

9 Since some homopolymerization was expected, the selectivity of the polymerization reaction

10 was evaluated by calculating the copolymer fraction of all formed polymer (i.e. the graft efficiency

11 (GE\%)) using formula 2.

$12 \quad G E \%=\frac{m_{N S}+m_{W S}-m_{X}}{m_{N S}+m_{W S}-m_{X}+m_{H P}} \times 100 \%$

13 where $m_{H P}$ is the mass of the homopolymer.

14 The grafting was verified by Fourier transform infrared (FTIR) spectroscopy. Infrared spectra 15 of the starting materials and all products were recorded with a Nicolet 750 Magna device as an 16 attenuated total reflection (ATR) measurement to confirm the presence of new functional groups 17 after modification. 
1 Scheme 1. Product separation and purification diagram.

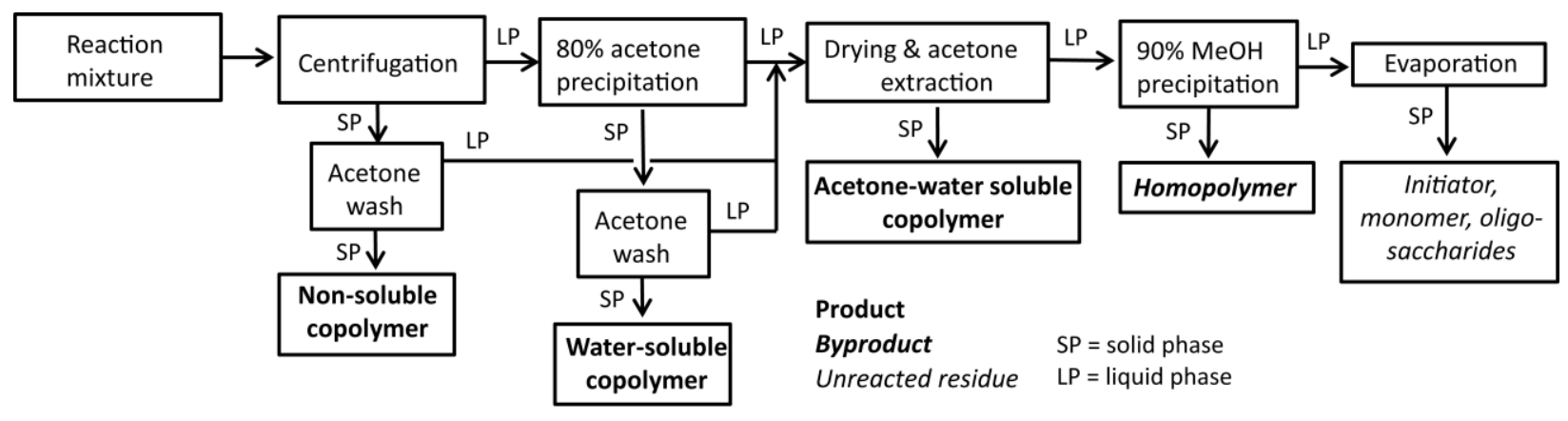

3 TLC analyses to quantify free sugars in grafted xylans.

4 The Araf to Xylp ratio of grafted and ungrafted xylans was determined to predict the grafted

5 position of the GMA copolymer. Approximately $1 \mathrm{mg}$ of each xylan sample in $120 \mu \mathrm{L}$ of $5 \mathrm{mM}$

6 MES (2-(N-morpholino) ethanesulfonic acid sodium) buffer ( $\mathrm{pH}$ 6.0) was incubated with $2.3 \mu \mathrm{g}$

7 of SthAbf62A, $1.35 \mu \mathrm{g} \mathrm{AXHd} 3,0.5 \mu \mathrm{g}$ E- XYLNP and $0.075 \mu \mathrm{g}$ E-BXSR-3KU at $40^{\circ} \mathrm{C}$ for $24 \mathrm{~h}$.

8 BSA was also added to each reaction mixture to a final concentration of $0.17 \mathrm{mg} / \mathrm{mL}$.

9 Following enzymatic digestion, 1-12 $\mu \mathrm{L}$ of each reaction (depending on product intensity), were

10 dried onto a silica plate for thin layer chromatography (TLC) analysis (Silica Gel 60 aluminum

11 sheet; Merck; VWR); $1 \mu \mathrm{L}$ of $1 \%$ cellobiose solution was added to each aliquot to serve as an

12 internal reference. Reaction products were separated on the TLC plate using 1-butanol : ethanol :

13 water (3:2:2) for $5 \mathrm{~h}$, stained using the orcinol staining solution. The components of staining

14 solution in final $500 \mathrm{ml}$ were as follows: $380 \mathrm{ml}$ of $99,5 \%$ ethanol, $50 \mathrm{ml}$ of $95-97 \% \mathrm{H} 2 \mathrm{SO} 4,1 \mathrm{~g}$

15 orcinol (3,5-dihydroxytoluol or 5-methyl resorcinol), and brought to $500 \mathrm{ml}$ using milli-Q water.

16 TLC spots were integrated and analyzed with Image Lab 5.1 software. Samples of arabinose

$17(0.2 \%)$, xylose $(0.2 \%)$ and cellobiose $(0.1 \%)$ were also run in parallel to track product migration

18 and intensity. Each fraction of the grafted xylan (i.e., water-soluble, water insoluble;

19 acetone/water-soluble soluble) were analyzed separately. The resulting Araf:Xyl $p$ ratios were then 
1 normalized to the percent of the corresponding fraction in the total grafted xylan. The quantity of

2 Araf and Xylp released from both grafted and untreated WAX was also verified by HPLC, as

3 described above

4 Adsorption of xylans to cellulose

5 The adsorption of enzyme treated WAX on regenerated cellulose was studied before and after

6 graft copolymerization. The model surfaces were prepared by spin-coating $\mathrm{SiO} 2$ sensors (Biolin

7 Scientific, Sweden) with trimethylsilyl cellulose (TMSC, DS $2.3^{46}$ ) dissolved in toluene (10 g

$8 \mathrm{~L}^{-1}$ ), and the TMSC surfaces were then regenerated using $10 \% \mathrm{HCl}$ vapor. Measurements by

9 quartz crystal microbalance with dissipation (QCM-D) were performed with a Q-Sense (Västra

10 Frölunda, Sweden) E4 instrument with controlled flow. The water-soluble copolymer fractions

11 were used to represent the grafted xylans. The samples were dissolved in deionized water at a

12 concentration of $0.5 \mathrm{~g} \mathrm{~L}^{-1}$, passed through $0.45 \mu \mathrm{m}$ syringe filters, and pumped at constant rate of

$130.1 \mathrm{~mL} / \mathrm{min}$ through the measurement chambers. The polysaccharide solutions were added after

14 first acquiring a stable baseline with ultrapure (milli-Q) water. The instrument recorded changes

15 in both resonance frequency and dissipation of the sensor. The fundamental resonance frequency

16 was $5 \mathrm{MHz}$, and the overtones at 15, 25, 35, 45, 55, and $65 \mathrm{MHz}$ were recorded. Adsorbed masses

17 were calculated from the 7th overtones with the Sauerbrey equation (3). Dissipation (D) is defined

18 by equation (4) and is proportional to the ratio between dissipated and stored oscillation energy. ${ }^{47}$

$19 \Delta m=\frac{C \Delta f}{n}$,

20 where $\Delta m$ is the adsorbed mass, $C$ is the device sensitivity constant $\left(0.177 \mathrm{mg} \mathrm{s} \mathrm{m}^{-2}\right.$, reported by

21 manufacturer), $\Delta f$ is the change in oscillation frequency, and $\mathrm{n}$ is the overtone number.

$22 \quad D=\frac{E_{\text {diss }}}{2 \pi E_{\text {stored }}}$, 
1 where $E_{\text {diss }}$ is the energy dissipated during one oscillation $E_{\text {stored }}$ is the energy stored.

\section{RESULTS and DISCUSSION}

\section{Characterization of ungrafted xylan preparations}

5 We investigated the potential to control the water solubility, graft yield, and adsorption

6 properties of xylan-GMA copolymers through pre-enzyme treatments that selectively removed $\alpha$ -

7 L-Araf branching substituents prior to the graft polymerization. Specifically, AXHd3 was used to

8 remove $\alpha$-L-Araf $(1 \rightarrow 3)$ from di-substituted Xyl $p$ backbone residues, thereby generating

9 WAX_AXHd3 (Figure 1). Alternatively, SthAbf62A targeted $\alpha$-L-Araf $(1 \rightarrow 3)$ in mono-

10 substituted Xyl $p$, generating WAX_SthAbf62A. Finally, AXHd3 and SthAbf62A were used

11 together to generate WAX_AXHd3_SthAbf62A.

12 The extent and position of Araf removal was confirmed by measuring both the released Araf

13 (Figure 2) and analyzing the residual xylan by ${ }^{1} \mathrm{H}$ NMR (Figures 3, S1). The analysis of released

14 Araf confirmed that approximately $20 \%$ of total Araf subunits were released by AXHd $3,30 \%$

15 of total Araf were released by SthAbf62A, and $70 \%$ of total Araf were removed when combining

16 AXHd3 and SthAbf62A activities. Consistent with previous studies, ${ }^{48}{ }^{1} \mathrm{H}$ NMR analyses of

17 residual xylans indicated that approximately $30 \%$ of $\alpha$-L-Araf $(1 \rightarrow 3)$ on di-substituted Xylp

18 remained in WAX_AXHd3, whereas approximately $20 \%$ of $\alpha$-L-Araf $(1 \rightarrow 3)$ from mono-

19 substituted Xylp remained in WAX_SthAbf62A. Similarly, WAX_AXHd3_SthAbf62A retained

20 approximately $40 \%$ of di-substituted Xylp and $30 \%$ mono-substituted Xylp. 


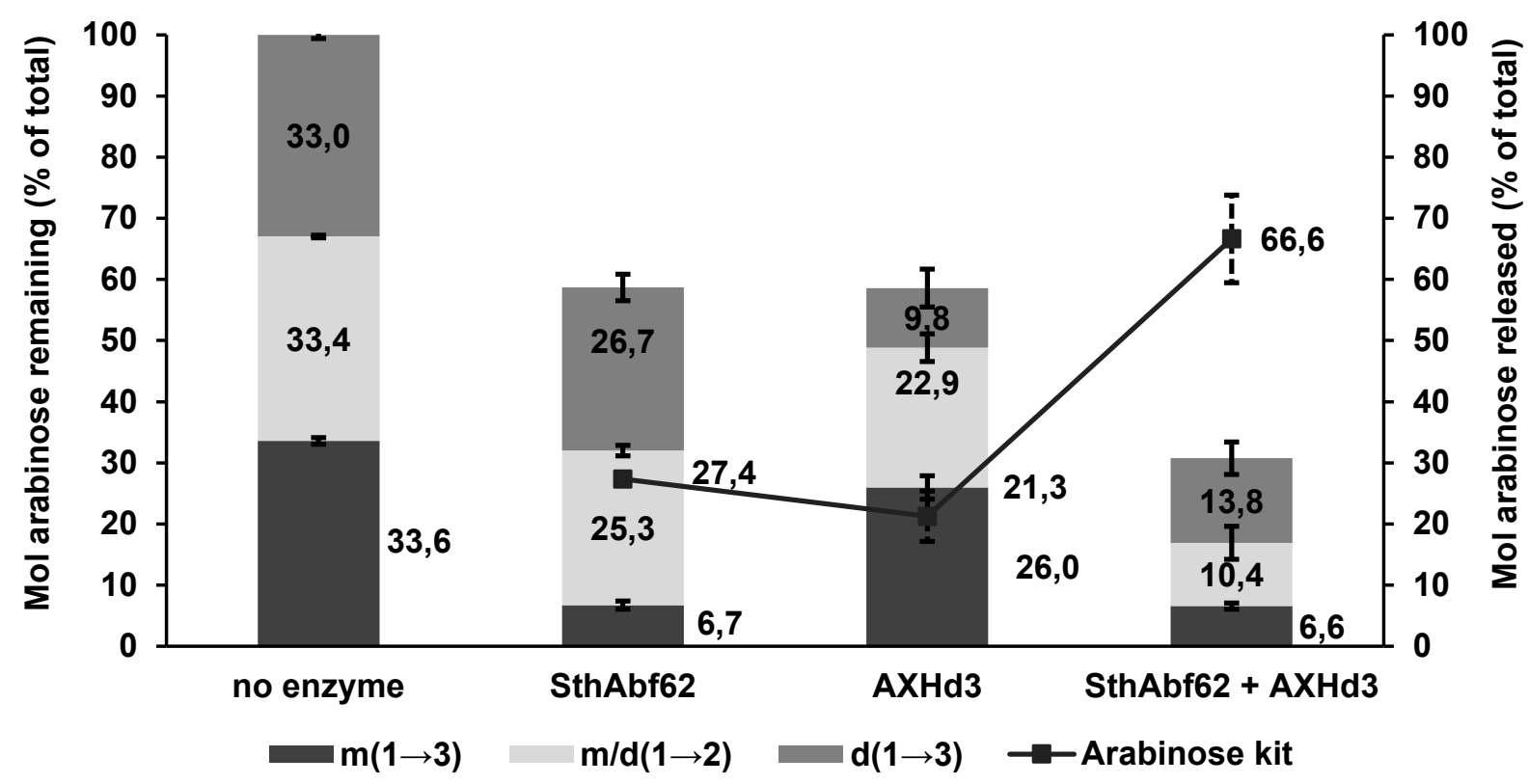

2 Figure 2. Araf remaining in enzyme treated and control wheat arabinoxylan samples determined

3 by ${ }^{1} \mathrm{H}$ NMR (NMR) (left $\mathrm{x}$-axis; shown as bars) and Araf released as measured by the L-

4 Arabinose Assay Kit (right $\mathrm{x}$-axis; shown as square points connected by a solid line). $\mathrm{m}(1 \rightarrow 3)$

5 refers to L-Araf $(1 \rightarrow 3)$ in mono-substituted Xyl $p$; $\mathrm{d}(1 \rightarrow 3)$ refers to $\alpha$-L-Ara $f(1 \rightarrow 3)$ in di-

6 substituted Xyl $p ; \mathrm{m} / \mathrm{d}(1 \rightarrow 2)$ refers to $\alpha$-L-Araf $(1 \rightarrow 2)$ in di-substituted Xyl $p$. 

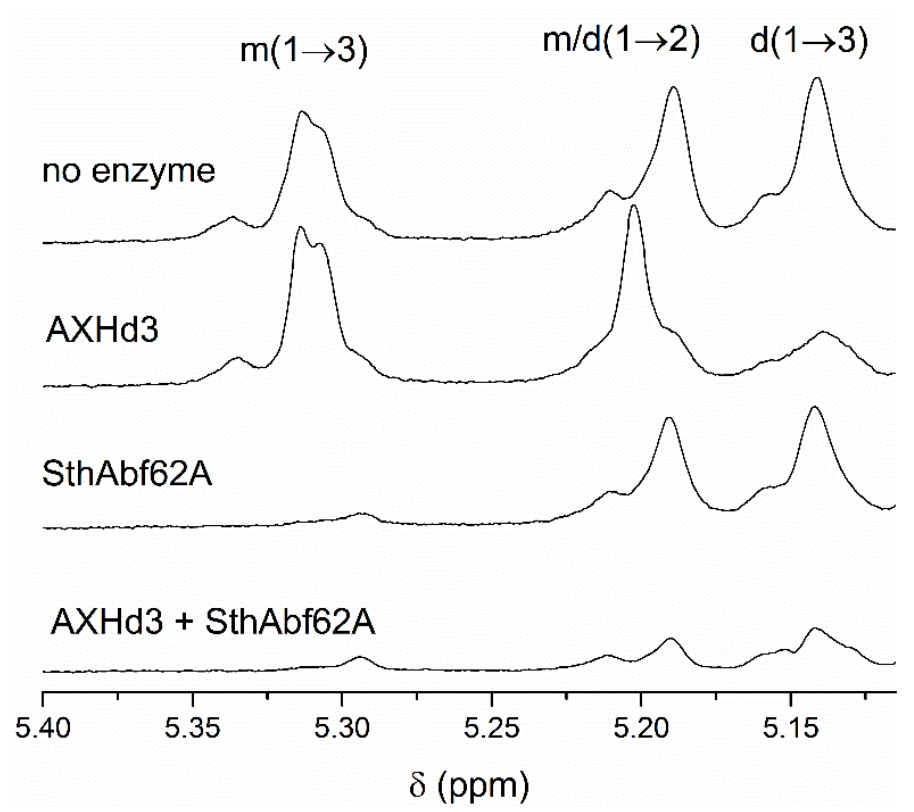

2 Figure 3. Anomeric signals in the ${ }^{1} \mathrm{H}$ NMR spectra of each arabinoxylan preparations in $\mathrm{D}_{2} \mathrm{O}$. $3 \mathrm{~m}(1 \rightarrow 3)$ refers to L-Ara $(1 \rightarrow 3)$ in mono-substituted Xyl $p(5.27-5.35 \mathrm{ppm}) ; \mathrm{m} / \mathrm{d}(1 \rightarrow 2)$ refers to $4 \quad \alpha$-L-Ara $f(1 \rightarrow 2)$ in mono-and di-substituted Xyl $p(5.17-5.23)$; d $(1 \rightarrow 3)$ refers to $\alpha$-L-Ara $f(1 \rightarrow 3)$ 5 in di-substituted Xyl $p(5.13-5.17 \mathrm{ppm})$.

6 Selective removal of Araf substituents was expected to promote the aggregation of resulting 7 xylan preparations, impacting their water solubility and chemical reactivity. Therefore, DLS was 8 used to characterize the water solubility and particle size distribution of each xylan sample. Since 9 decreased solubility would likely increase sample turbidity, visible light transmittance was also 10 determined. Whereas the particle size of WAX and WAX_AXHd3 were similar, the particle size 11 of WAX_SthAbf62A and WAX_AXHd3_SthAbf62A were increased by 1.5 and 4 times, 12 respectively; the double enzyme treatment also dramatically increased sample turbidity 13 (Figure 4). Since particle sizes were beyond the reliable range of DLS measurements, absolute 14 particles sizes could not be determined; however, the results were consistent with turbidity 15 measurements and confirmed increasing aggregation with increasing, unsubstituted Xyl $p$. 


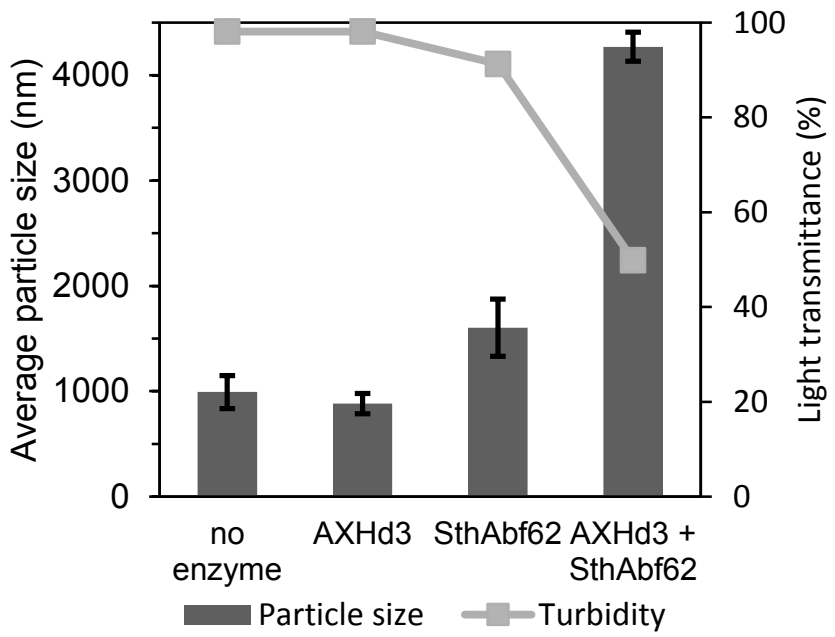

3 Figure 4. Average particle size (bars) and light transmittance at $700 \mathrm{~nm}$ (line) of ungrafted xylans.

\section{Graft copolymerization}

5 Enzymatically treated WAX samples were graft copolymerized with GMA in aqueous solution

6 using identical conditions. Three product fractions were then separated based on their solubility,

7 and the overall graft yield and efficiency were determined gravimetrically.

8 Partial removal of Araf increased the graft yield (Figure 5), producing more copolymer with all 9 enzyme-treated xylans. The most significant increase was observed for WAX_SthAbf62A, which

10 was also characterized by comparatively high particle size. As previously observed, the lower 11 water solubility of WAX_SthAbf62A and WAX_AXHd3_SthAbf62A improved the product yield

12 by facilitating copolymer separation. ${ }^{26}$ However, the lower water solubility of these xylan

13 preparations also impacted their dispersion in the reaction mixture, leading to higher variance in

14 product yields. Predictably, the water solubility of each WAX substrate was also reflected by the

15 solubility of corresponding graft copolymers. Whereas WAX and WAX_AXHd3 mainly produced 
1 a water soluble copolymer, the fraction of water insoluble products increased up to 14 times for

2 WAX_SthAbf62A, and up to 26 times for WAX_AXHd3_SthAbf62A.

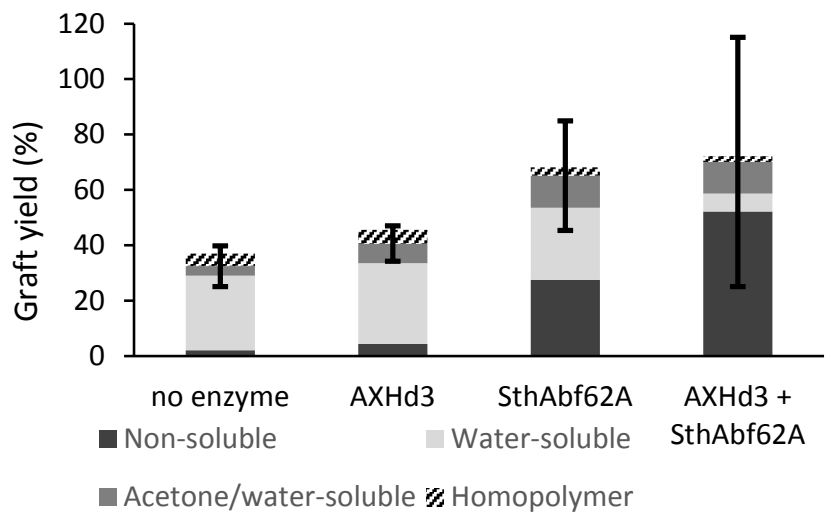

4 Figure 5. Yield by product fraction relative to the mass of xylan.

5 FTIR analysis of water soluble and water insoluble fractions showed characteristic absorption 6 peaks for both xylan and poly(glycidyl methacrylate) (PGMA); the carbonyl signal of PGMA $7\left(1725 \mathrm{~cm}^{-1}\right)$ was also present in the acetone/water-soluble soluble and homopolymer fractions 8 (Figure 6). The characteristic carbohydrate hydroxyl group peak at $1025 \mathrm{~cm}^{-1}$ was weak in the 9 acetone/water-soluble soluble fraction, which was also characterized by a strong absorption band 10 near $1660 \mathrm{~cm}^{-1}$ corresponding to carbon-carbon double bonds. This observation suggests that a 11 substantial part of the acetone/water-soluble soluble copolymer was formed via an acid-catalyzed 12 ring-opening reaction of free GMA with heavily grafted or short-chain xylan copolymers, rather 13 than radical polymerization. 


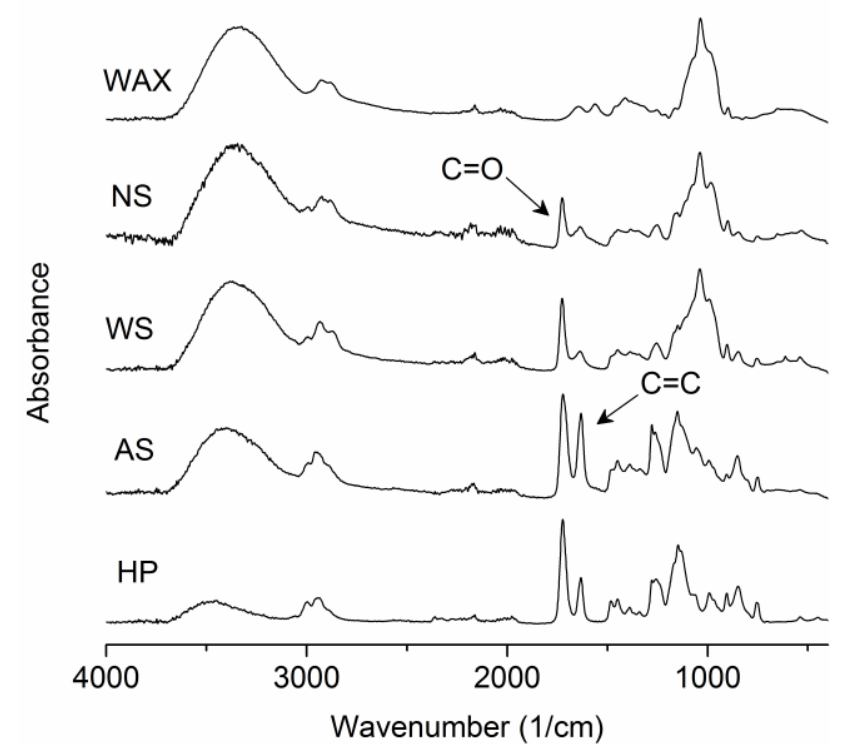

2 Figure 6. FTIR spectra of different product fractions. Abbreviations: WAX, ungrafted xylan;

3 NS, non-soluble copolymer; WS, water-soluble copolymer; AS, acetone/water-soluble soluble

4 copolymer; HP, homopolymer (PGMA).

$5 \quad$ TLC analysis of free sugars in grafted xylan samples

6 To determine whether the cerium oxidation and subsequent grafting preferentially targeted

7 particular Araf and Xylp positions, AXHd3 and SthAbf62A along with endo-1,4- $\beta$-D-xylanase (E-

$8 \mathrm{XYLNP}$ ) and $\beta$-D-xylosidase (E-BXSR-3KU) were used to treat and then analyze the ungrafted

9 and grafted WAX samples. More specifically, each of the four xylan-GMA copolymers generated

10 in this study were simultaneously treated with AXHd3, SthAbf62A, $\beta$-D-xylanase and $\beta$ -

11 xylosidase. Ungrafted xylan was used as reference. It was hypothesized that if preferential grafting

12 of GMA to either Araf or Xyl $p$ had occurred, then the ratio of Araf:Xyl $p$ would differ for a given

13 xylan sample before and after the grafting reaction, assuming that enzyme activity is hindered by

14 the graft co-polymer. 
2 well to Xylp and Araf residues in each xylan sample, also confirming that cerium ion oxidation

3 did not discriminate between main chain and branching sugars Figure 7). Notably, sugars were

4 also released from the acetone/water-soluble soluble fraction, supporting the assignment of this

5 fraction as a copolymer rather than homopolymer.

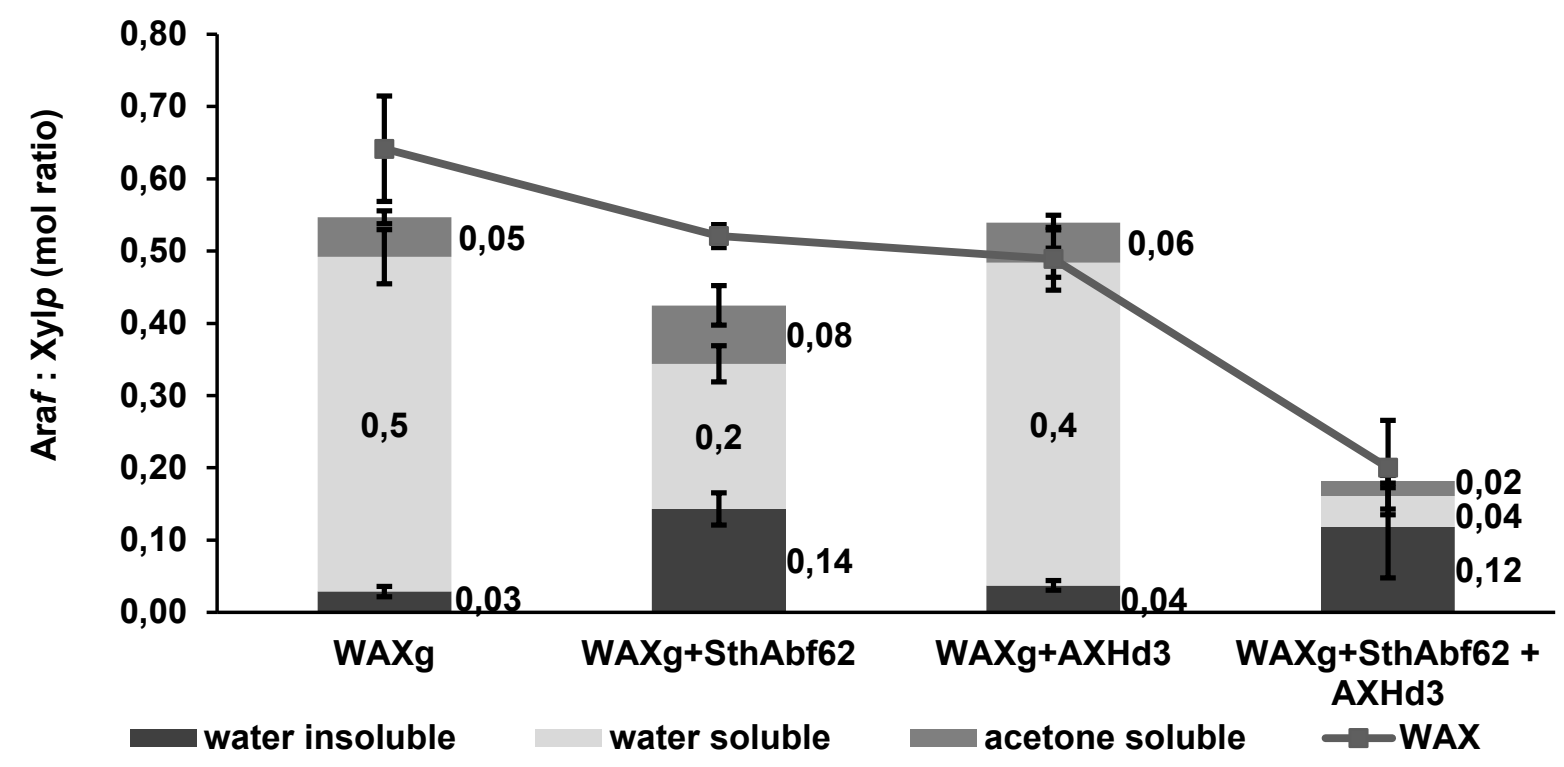

7 Figure 7. Araf:Xyl $p$ ratio calculated from TLC analyses. Ungrafted wheat arabinoxylan (WAX)

8 served as reference and comprised only one fraction (black square symbols), whereas the grafted

9 xylan (WAXg) contained three differently soluble fractions, namely insoluble, water-soluble,

10 and acetone/water-soluble soluble (values represented as stacked bars).

\section{Adsorption of xylans to cellulose}

12 Effects of substitution pattern and polymer grafting to the adsorption behavior of WAX to 13 regenerated cellulose were studied by QCM-D. Hemicellulose adsorption to cellulose fibers can 14 improve their tensile strength, and offers a pathway to their surface-selective functionalization by 
1 using derivatized xylan. ${ }^{30,32,49}$ However, the stability of xylan adsorption to cellulose is dependent

2 on xylan molecular weight and substitution pattern, ${ }^{32,34}$ xylan solubility in water, and the colloidal

3 stability of the xylan molecules. ${ }^{40}$ Modification of the Araf substitution patterns of WAX by using

4 appropriate enzymes has also been reported to increase its binding capacity to cellulose and enable 5 adjustment of the viscoelastic properties of the adsorbed layer. ${ }^{32}$

6 The slope of change in dissipation $(\Delta D)$ versus change in frequency $(\Delta f)$ reflects the viscoelastic 7 properties of the adsorbed layer, where a higher slope indicates a more viscous surface layer.

8 Accordingly, the $\Delta \mathrm{D} / \Delta \mathrm{f}$ data plotted in Figure 8 distinguished untreated WAX and 9 WAX_AXHd3, from WAX_SthAbf62A and WAX_AXHd3_SthAbf62A, where the latter xylan 10 preparations formed more densely packed and less hydrated adsorption layers (Figure 8).

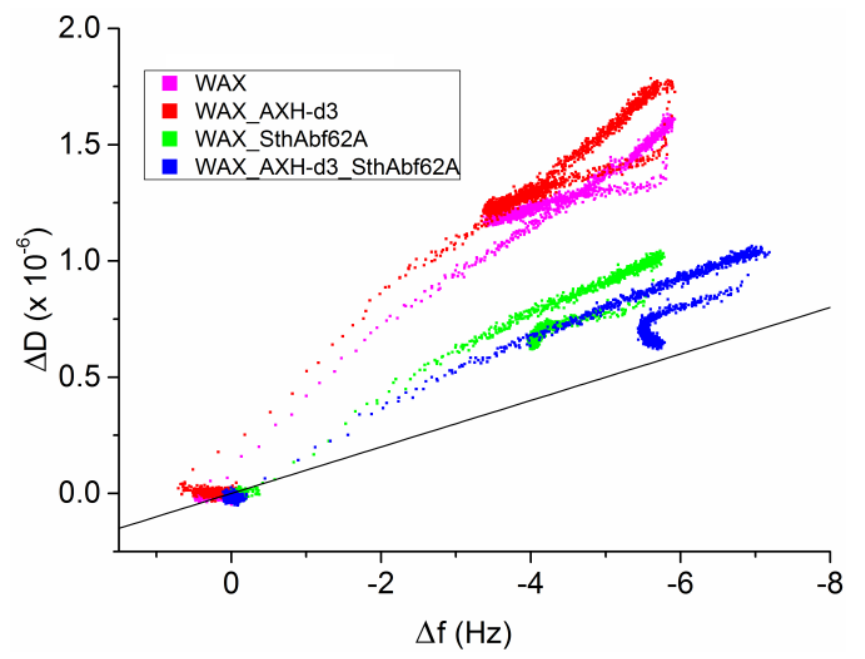

12 Figure 8. Change in dissipation versus frequency during adsorption of ungrafted xylans. The

13 black diagonal shows the border between elastic and viscoelastic domains.

14 Roughly halfway to maximum adsorption, the curves of all xylan types exhibited an inflection

15 point, indicating slightly more elastic character of the outer adsorbed layer. Several earlier studies

16 have noted similar phenomenon and some have attributed it to the formation of a secondary adlayer 
1 based on xylan-xylan attraction, after saturation of the cellulose surface. ${ }^{32,35,50}$ In all cases,

2 approximately $70 \%$ of the xylan remained adsorbed to the cellulose surface following extensive

3 washing with water (Table S1). Moreover, desorption curves overlapped with corresponding

4 adsorption curves, indicating that the viscoelastic properties of the adsorbed layers were not

5 changed during rinsing.

6 Following grafting of WAX, in our study, between $30-50 \%$ of the xylan samples, remained

7 adsorbed to the cellulose surface, regardless of the enzyme treatment (Figure 9A, Table S1). The

$8 \Delta \mathrm{D} / \Delta \mathrm{f}$ data plotted in Figure 9 also revealed an apparent two-stage adsorption/desorption

9 phenomenon (Figure 9B). More specifically, initial adsorption proceeded quickly producing a

10 rather rigid (elastic) layer. This was followed by the formation of a more swollen top layer, as

11 further adsorption abated. The resulting outermost layer shed rapidly during rinsing; however, the

12 underlying xylan coating was more stable and appeared to require water adsorption and/or

13 rearrangements leading to increased dissipation prior to detachment from the cellulose surface.

14 The difference in $\Delta \mathrm{D} / \Delta \mathrm{f}$ plots generated using ungrafted versus grafted xylans can be explained

15 by the relative hydrophobicity of the graft copolymer, which also increased xylan aggregation

16 (Figure 4). With less bound water, corresponding aggregates would form a comparatively elastic

17 layer on the underlying cellulose surface. After saturating the cellulose surface, subsequent

18 stacking of the xylan aggregates would likely lead to water entrapment, significantly increasing

19 the viscosity of the add-layer. 

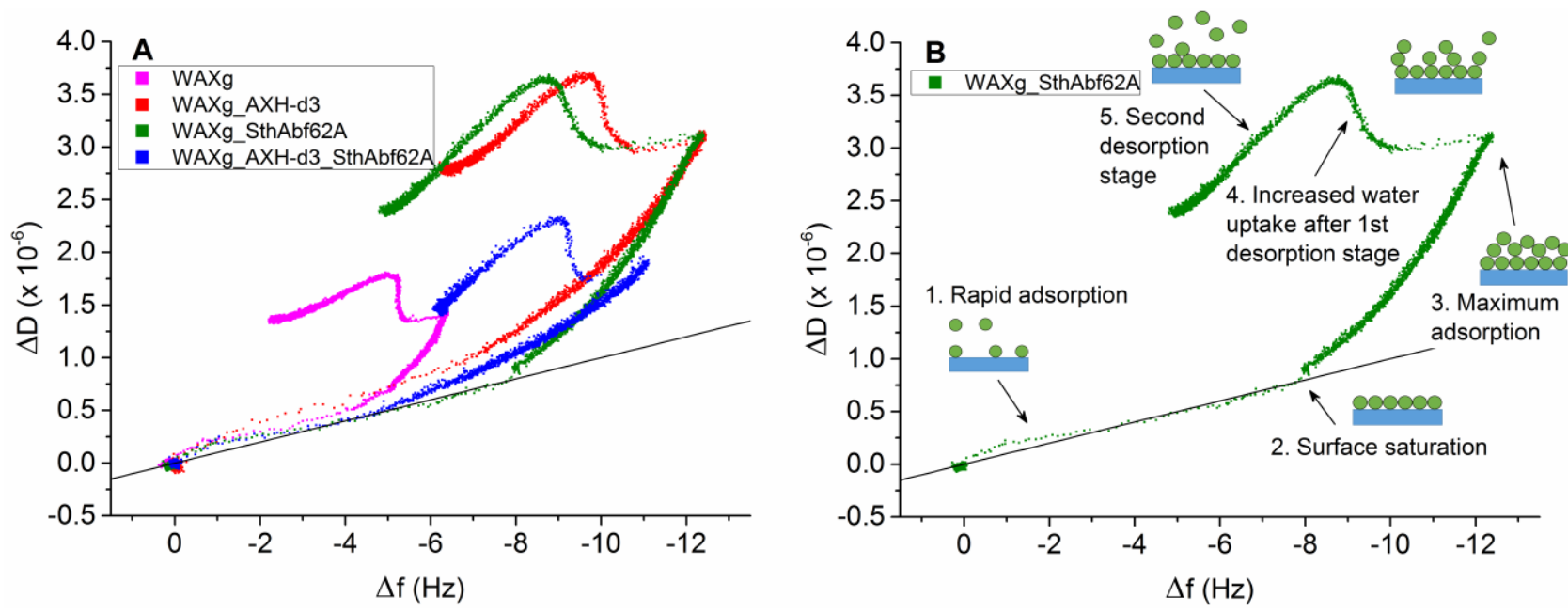

Figure 9. Change in dissipation versus frequency during adsorption of all grafted xylans (A), and different stages of

adsorption/desorption illustrated on a single curve (B). The black diagonal shows the border between elastic and viscoelastic domains. 
1 Adsorption studies with hydrophobized hemicellulose are not very common. In one other case,

2 however, fatty acids and short polydimethylsiloxanes were added to the reducing end of

3 galactoglucomannan using reductive amination, which was found to increase its adsorption to

4 cellulose by lowering water solubility while retaining affinity to the cellulose surface. ${ }^{51}$ Distinct

5 from the adlayers formed by the xylan copolymers generated herein, specific modification of the

6 reducing end of galactoglucomannan promoted bilayer formation. ${ }^{51}$ These differences highlight

7 options to regulate both the chemical functionality and organization of hemicellulose coatings.

\section{CONCLUSIONS}

10 In the current study, we investigated the potential to regulate the properties of arabinoxylan-

11 based copolymers through enzymatic removal of specific Araf substituents. Whereas removal of $12 \alpha$-L-Araf $(1 \rightarrow 3)$ from di-substituted Xyl $p$ did not detectably impact xylan solubility, removal $\alpha$ -

13 L-Araf $(1 \rightarrow 3)$ from mono-substituted Xylp subunits led to product precipitation. Moreover,

14 subsequent graft copolymerization with GMA showed that by decreasing the water solubility of

15 the xylan, higher graft yields could be achieved. TLC analysis of enzymatically depolymerized

16 reaction products also confirmed that redox initiation was equally effective with Araf and Xylp

17 substituents.

18 QCM-D analyses of xylan adsorption to cellulose showed that arabinofuranosidase treatment of

19 arabinoxylans can control the viscoelastic character of the coated layer; however, subsequent xylan

20 grafting with GMA outweighed this impact of enzyme pretreatment. Whereas the gains in xylan

21 adsorption to cellulose achieved through enzyme pretreatment could be retained when substituting

22 GMA for other functional monomers, enzyme pretreatment is expected to consistently benefit the 23 recovery of resulting xylan copolymers. 


\section{ASSOCIATED CONTENT}

\section{Supporting Information.}

Full ${ }^{1} \mathrm{H}$ NMR spectra of all arabinoxylan preparations, and adsorbed masses of xylans measured by QCM-D.

This material is available free of charge via the Internet at http://pubs.acs.org.

\section{AUTHOR INFORMATION}

\section{Corresponding Author}

* Emma R. Master

Department of Chemical Engineering and Applied Chemistry

University of Toronto

200 College Street, Toronto, ON, M3S 3E5

Phone: +1 - 416-946-7861

Fax: +1 - 416-978-8605

E-mail: emma.master@utoronto.ca

\section{Notes}

The authors declare no competing financial interest. 


\section{Author Contributions}

The manuscript was written through contributions of all authors. All authors have given approval to the final version of the manuscript. $\$$ These authors contributed equally.

\section{ACKNOWLEDGMENT}

We thank Dr. W. Wang (U Toronto) for supplying the SthAbf62A $\alpha$-arabinofuranosidase. Funding for this project was provided by the Graduate School for Biomass Refining (BIOREGS) to K. Littunen from the Academy of Finland, a FiDiPro Fellowship to E. Master from the Finnish Funding Agency for Technology and Innovation (Tekes), and the ERC Consolidator Grant BHIVE (648925) to E. Master.

\section{REFERENCES}

(1) Spiridon, I.; Popa, V. I. In Monomers, Polymers and Composites from Renewable Resources; Belgacem, M. N., Gandini, A., Eds.; Elsevier, 2008; pp 289-304.

(2) Ebringerová, A.; Hromádková, Z.; Heinze, T. Hemicellulose. Adv. Polym. Sci. 2005, 186, $1-67$.

(3) Scheller, H. V; Ulvskov, P. Hemicelluloses. Annu. Rev. Plant Biol. 2010, 61, 263-289.

(4) Pawar, P. M.-A.; Koutaniemi, S.; Tenkanen, M.; Mellerowicz, E. J. Acetylation of Woody Lignocellulose: Significance and Regulation. Front. Plant Sci. 2013, 4: 118.

(5) Izydorczyk, M. S.; Biliaderis, C. G. Cereal Arabinoxylans: Advances in Structure and Physicochemical Properties. Carbohydr. Polym. 1995, 28 (1), 33-48. 
(6) Ebringerová, A. Structural Diversity and Application Potential of Hemicelluloses. Macromol. Symp. 2006, 232, 1-12.

(7) Hansen, N. M. L.; Plackett, D. Sustainable Films and Coatings from Hemicelluloses: A Review. Biomacromolecules 2008, 9 (6), 1493-1505.

(8) Edlund, U.; Ryberg, Y. Z.; Albertsson, A.-C. Barrier Films from Renewable Forestry Waste. Biomacromolecules 2010, 11 (9), 2532-2538.

(9) Zhang, Y.; Pitkänen, L.; Douglade, J.; Tenkanen, M.; Remond, C.; Joly, C. Wheat Bran Arabinoxylans: Chemical Structure and Film Properties of Three Isolated Fractions. Carbohydr. Polym. 2011, 86 (2), 852-859.

(10) Mikkonen, K. S.; Tenkanen, M. Sustainable Food-packaging Materials Based on Future Biorefinery Products: Xylans and Mannans. Trends Food Sci. Technol. 2012, 28 (2), 90-102.

(11) Mikkonen, K. S.; Parikka, K.; Ghafar, A.; Tenkanen, M. Prospects of Polysaccharide Aerogels as Modern Advanced Food Materials. Trends Food Sci. Technol. 2013, 34 (2), 124-136.

(12) Farhat, W.; Venditti, R. A.; Hubbe, M.; Taha, M.; Becquart, D. F.; Ayoub, D. A. A Review of Water-resistant Hemicellulose-based Materials: Processing and Applications. ChemSusChem

(13) Péroval, C.; Debeaufort, F.; Despré, D.; Voilley, A. Edible Arabinoxylan-based Films. 1. Effects of Lipid Type on Water Vapor Permeability, Film Structure, and Other Physical Characteristics. J. Agric. Food Chem. 2002, 50 (14), 3977-3983.

(14) Zhang, P.; Whistler, R. L. Mechanical Properties and Water Vapor Permeability of Thin Film from Corn Hull Arabinoxylan. J. Appl. Polym. Sci. 2004, 93 (6), 2896-2902. 
(15) Höije, A.; Gröndahl, M.; Tømmeraas, K.; Gatenholm, P. Isolation and Characterization of Physicochemical and Material Properties of Arabinoxylans from Barley Husks. Carbohydr. Polym. 2005, 61 (3), 266-275.

(16) Höije, A.; Sternemalm, E.; Heikkinen, S.; Tenkanen, M.; Gatenholm, P. Material Properties of Films from Enzymatically Tailored Arabinoxylans. Biomacromolecules 2008, 9 (7), $2042-2047$.

(17) Sternemalm, E.; Höije, A.; Gatenholm, P. Effect of Arabinose Substitution on the Material Properties of Arabinoxylan Films. Carbohydr. Res. 2008, 343 (4), 753-757.

(18) Mikkonen, K. S.; Heikkinen, S.; Soovre, A.; Peura, M.; Serimaa, R.; Hyvo, L.; Talja, R. A.; Helén, H.; Hyvönen, L.; Tenkanen, M. Films from Oat Spelt Arabinoxylan Plasticized with Glycerol and Sorbitol. J. Appl. Polym. Sci. 2009, 114 (1), 457-466.

(19) Stevanic, J. S.; Joly, C.; Mikkonen, K. S.; Pirkkalainen, K.; Serimaa, R.; Rémond, C.; Toriz, G.; Gatenholm, P.; Tenkanen, M.; Salmen, L. Bacterial Nanocellulose-reinforced Arabinoxylan Films. J. Appl. Polym. Sci. 2011, 122 (2), 1030-1039.

(20) Escalante, A.; Gonçalves, A.; Bodin, A.; Stepan, A.; Sandström, C.; Toriz, G.; Gatenholm, P. Flexible Oxygen Barrier Films from Spruce Xylan. Carbohydr. Polym. 2012, 87 (4), 2381-23

(21) Yaich, A. I.; Edlund, U.; Albertsson, A.-C. Wood Hydrolysate Barriers: Performance Controlled via Selective Recovery. Biomacromolecules 2012, 13 (2), 466-473.

(22) Gröndahl, M.; Eriksson, L.; Gatenholm, P. Material Properties of Plasticized Hardwood Xylans for Potential Application as Oxygen Barrier Films. Biomacromolecules 2004, 5 (4), 1528 1535. 
(23) Saadatmand, S.; Edlund, U.; Albertsson, A.-C.; Danielsson, S.; Dahlman, O.; Karlström, K. Turning Hardwood Dissolving Pulp Polysaccharide Residual Material into Barrier Packaging. Biomacromolecules 2013, 14 (8), 2929-2936.

(24) Yaich, A. I.; Edlund, U.; Albertsson, A.-C. Adapting Wood Hydrolysate Barriers to High Humidity Conditions. Carbohydr. Polym. 2014, 100, 135-142.

(25) Laine, C.; Harlin, A.; Hartman, J.; Hyvärinen, S.; Kammiovirta, K.; Krogerus, B.; Pajari, H.; Rautkoski, H.; Setälä, H.; Sievänen, J.; Uotila, J.; Vähä-Nissi, M. Hydroxyalkylated Xylans Their Synthesis and Application in Coatings for Packaging and Paper. Ind. Crops Prod. 2013, 44, $692-704$.

(26) Littunen, K.; Kilpeläinen, P.; Junka, K.; Sipponen, M.; Master, E. R.; Seppälä, J. Effect of Xylan Structure on Reactivity in Graft Copolymerization and Subsequent Binding to Cellulose. Biomacromolecules 2015, 16 (4), 1102-1111.

(27) Biely, P.; Singh, S.; Puchart, V. Towards Enzymatic Breakdown of Complex Plant Xylan Structures: State of the Art. Biotechnol. Adv. 2016, 34 (7), 1260-1274.

(28) Siguier, B.; Haon, M.; Nahoum, V.; Marcellin, M.; Burlet-Schiltz, O.; Coutinho, P. M.; Henrissat, B.; Mourey, L.; Donohue, M. J. O.; Berrin, J.-G.; Tranier, S.; Dumon, C. First Structural Insights into $\alpha$-L-Arabinofuranosidases from the Two GH62 Glycoside Hydrolase Subfamilies. $J$. Biol. Chem. 2014, 289 (8), 5261-5273.

(29) Van Laere, K. M. J.; Beldman, G.; Voragen, A. G. J. A New Arabinofuranohydrolase from Bifidobacterium adolescentis Able to Remove Arabinosyl Residues from Double-substituted Xylose Units in Arabinoxylan. Appl. Microbiol. Biotechnol. 1997, 47 (3), 231-235. 
(30) Köhnke, T.; Pujolras, C.; Roubroeks, J. P.; Gatenholm, P. The Effect of Barley Husk Arabinoxylan Adsorption on the Properties of Cellulose Fibres. Cellulose 2008, 15 (4), 537-546

(31) Pitkänen, L.; Tuomainen, P.; Virkki, L.; Tenkanen, M. Molecular Characterization and Solution Properties of Enzymatically Tailored Arabinoxylans. Int. J. Biol. Macromol. 2011, 49 (5), 963-969.

(32) Köhnke, T.; Östlund, Å.; Brelid, H. Adsorption of Arabinoxylan on Cellulosic Surfaces: Influence of Degree of Substitution and Substitution Pattern on Adsorption Characteristics. Biomacromolecules 2011, 12 (7), 2633-2641.

(33) Heikkinen, S. L.; Mikkonen, K. S.; Pirkkalainen, K.; Serimaa, R.; Joly, C.; Tenkanen, M. Specific Enzymatic Tailoring of Wheat Arabinoxylan Reveals the Role of Substitution on Xylan Film Properties. Carbohydr. Polym. 2013, 92 (1), 733-740.

(34) Kabel, M. A.; van den Borne, H.; Vincken, J.-P.; Voragen, A. G. J.; Schols, H. A. Structural Differences of Xylans Affect their Interaction with Cellulose. Carbohydr. Polym. 2007, 69 (1), 94-105.

(35) Eronen, P.; Österberg, M.; Heikkinen, S.; Tenkanen, M.; Laine, J. Interactions of Structurally Different Hemicelluloses with Nanofibrillar Cellulose. Carbohydr. Polym. 2011, 86 (3), 1281-1290.

(36) Busse-Wicher, M.; Li, A.; Silveira, R. L.; Pereira, C. S.; Tryfona, T.; Gomes, T. C. F.; Skaf, M. S.; Dupree, P. Evolution of Xylan Substitution Patterns in Gymnosperms and Angiosperms: Implications for Xylan Interaction with Cellulose. Plant Physiol. 2016, 171 (4), $2418-2431$. 
(37) Vincken, J. P.; de Keizer, A.; Beldman, G.; Voragen, A. G. J. Fractionation of Xyloglucan Fragments and their Interaction with Cellulose. Plant Physiol. 1995, 108 (4), 1579-1585.

(38) Pereira, C. S.; Silveira, R. L.; Dupree, P.; Skaf, M. S. Effects of Xylan Side Chain Substitutions on Xylan-cellulose Interactions and Implications for Thermal Pretreatment of Cellulosic Biomass. Biomacromolecules 2017, DOI: 10.1021/acs.biomac.7b00067

(39) O'Connell, D. W.; Birkinshaw, C.; O'Dwyer, T. F. A Chelating Cellulose Adsorbent for the Removal of $\mathrm{Cu}(\mathrm{II})$ from Aqueous Solutions. J. Appl. Polym. Sci. 2006, 99, 2888-2897.

(40) Wang, W.; Mai-Gisondi, G.; Stogios, P. J.; Kaur, A.; Xu, X.; Cui, H.; Turunen, O.;

Savchenko, A.; Master, E. R. Elucidation of the Molecular Basis for Arabinoxylan-debranching Activity of a Thermostable Family GH62 $\alpha$-L-Arabinofuranosidase from Streptomyces thermoviolaceus. Appl. Environ. Microbiol. 2014, 80 (17), 5317-5329.

(41) Schooneveld-Bergmans, M. E. F.; Beldman, G.; Voragen, A. G. J. Structural Features of (Glucurono)arabinoxylans Extracted from Wheat Bran by Barium Hydroxide. J. Cereal Sci. 1999, $29(1), 63-75$.

(42) Gruppen, H.; Hoffmann, R. A.; Kormelink, F. J. M.; Voragen, A. G. J.; Kamerling, J. P.; Vliegenthart, J. F. G. Characterisation by 1H NMR Spectroscopy of enzymically Derived Oligosaccharides from Alkali-extractable Wheat-flour Arabinoxylan. Carbohydr. Res. 1992, 233 (C), 45-64.

(43) Pastell, H.; Tuomainen, P.; Virkki, L.; Tenkanen, M. Step-wise Enzymatic Preparation and Structural Characterization of Singly and Doubly Substituted Arabinoxylo-oligosaccharides with Non-reducing End Terminal Branches. Carbohydr. Res. 2008, 343 (18), 3049-3057. 
(44) Pitkänen, L.; Virkki, L.; Tenkanen, M.; Tuomainen, P. Comprehensive Multidetector HPSEC Study on Solution Properties of Cereal Arabinoxylans in Aqueous and DMSO Solutions. Biomacromolecules 2009, 10 (7), 1962-1969.

(45) Sakamoto, T.; Ogura, A.; Inui, M.; Tokuda, S.; Hosokawa, S.; Ihara, H.; Kasai, N. Identification of a GH62 $\alpha$-L-Arabinofuranosidase specific for arabinoxylan Produced by Penicillium chrysogenum. Appl. Microbiol. Biotechnol. 2011, 90 (1), 137-146.

(46) Kontturi, E.; Thu, P. C.; Niemantsverdriet, J. W. H. Cellulose Model Surfaces - Simplified Preparation by Spin Coating and Characterization by X-ray Photoelectron Spectroscopy, Infrared Spectroscopy, and Atomic Force Microscopy. Langmuir 2003, 19 (13), 5735-5741.

(47) Eronen, P.; Junka, K.; Laine, J.; Österberg, M. Interaction Between Water-soluble Polysaccharides and Native Nanofibrillar Cellulose Thin Films. BioResources 2011, 6 (4), 42004217.

(48) Sørensen, H. R.; Jørgensen, C. T.; Hansen, C. H.; Jørgensen, C. I.; Pedersen, S.; Meyer, A. S. A Novel GH43 $\alpha$-L-Arabinofuranosidase from Humicola insolens: Mode of Action and Synergy with GH51 $\alpha$-L-Arabinofuranosidases on Wheat Arabinoxylan. Appl. Microbiol. Biotechnol. 2006, $73(4), 850-861$.

(49) Henriksson, B. Å.; Gatenholm, P. Controlled Assembly of Glucuronoxylans onto Cellulose Fibres. Holzforschung 2001, 55, 494-502.

(50) Selig, M. J.; Thygesen, L. G.; Felby, C.; Master, E. R. Debranching of Soluble Wheat Arabinoxylan Dramatically Enhances Recalcitrant Binding to Cellulose. Biotechnol. Lett. 2015, $37(3), 633-641$. 
(51) Lozhechnikova, A.; Dax, D.; Vartiainen, J.; Willför, S.; Xu, C.; Österberg, M. Modification of Nanofibrillated Cellulose Using Amphiphilic Block-structured Galactoglucomannans. Carbohydr. Polym. 2014, 110, 163-172. 
Table of Contents Graphic

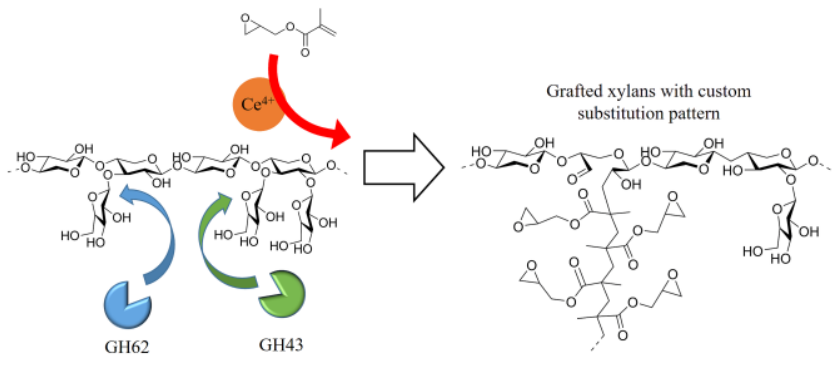

